as well as other local authorities. The Home Secretary suggests $^{3}$ liaison with housing authorities, voluntary organizations, local churches, and social-welfare charities. Charities may be able to help with their funds. The Home Secretary also suggests the provision of family advice centres where help can be sought and information and assistance given. Besides giving advice and guidance the councils will be empowered to give assistance in kind or in exceptional circumstances in cash. Assistance in kind may take such forms as bedding, kitchen equipment, or fuel, and cash assistance may be either by outright grant or by way of a loan. The councils will be unfettered in their decisions on the manner in which they will provide the required advice, guidance, and assistance, and all will have great opportunities for initiative and experiment. Provision will be made for periodic reports to the Home Secretary on the work done. It is perhaps a little surprising that the Home Secretary has not announced his intention of also giving effect on October 1 to section 45 of the Act, which would empower him and the county councils to conduct research, or assist other persons in conducting research, into any matter connected with his functions or the councils' functions under the various Children's Acts. Skilled investigators must be financed speedily to aid in the working out and application of the best ideas.

The 1963 Act contains many other provisions of great importance to the health and well-being of children, but they await a Ministerial order to give them life. To take but a few examples: there are new provisions regarding children and young persons in need of care, protection, or control ; the employment of children and young persons; the raising of the age of criminal responsibility to 10 years; and the giving of evidence by children in committal proceedings for sexual offences. The section dealing with the evidence of child witnesses of sexual assaults adopts in principle one of the suggestions made in a symposium on the subject in this journal. ${ }^{4}$ This was that children should not give evidence on committal proceedings but the accused person should have a copy of the trial statement.

Some of the provisions of the 1963 Act require little administrative preparation to put them into effect. Other provisions require no administrative preparations whatever-as, for instance, the sections providing for increases in penalties for cruelty to children, for sale of tobacco to children, and for failure to comply with court orders for the taking of precautions over cigarette machines extensively used by children. It is to be hoped that the whole Act will soon be put into effect.

\footnotetext{
1 Crueltv to and Neglect of Children. Report of a Joint Committee of the British Medical Association and the Magistrates Association, 1956. B.M.A. House, London.

2 Report of the Committee on Children and Young Persons, Home Office, 1960. H.M.S.O., London.

- Home Office Circular, No. 204/1963.
Brit. med. J., 1961, 2, 1628.
}

\section{JEJUNAL DIVERTICULA}

Intestinal diverticula are most commonly found in the colon and duodenum in man. ${ }^{1}$ Diverticulosis of the jejunum is a much rarer condition, though it has been recognized and reported with increasing frequency since the introduction of $x$-radiography with barium meals. ${ }^{2}$ For many years jejunal diverticula were thought likely to cause only abdominal symptoms. ${ }^{1}$ Vague abdominal discomfort, flatulence, borborygmi, and occasional colicky pain $^{3}$ were believed to be characteristic features, though complications such as perforation, ${ }^{4}$ obstruction, or volvulus ${ }^{1}$ were from time to time described. It is only in recent years that the far-reaching metabolic consequences of jejunal diverticula have been detected.

E. Montuschi ${ }^{5}$ in 1949 described a patient in whom steatorrhoea and hypoproteinaemic oedema were ascribed to "a low-grade inflammatory process of the diverticula." In $1955 \mathrm{~J}$. Badenoch and his colleagues ${ }^{6}$ and A. P. Dick reported a characteristic syndrome in which jejunal diverticulosis was associated with steatorrhoea and megaloblastic anaemia, occasionally also with neurological symptoms, and patients with these features have subsequently been reported from other centres. ${ }^{8-13} \mathrm{~W}$. T. Cooke and his colleagues $^{14}$ have now recorded their experience in a series of 33 patients with jejunal diverticulosis. They found that only four of these patients were asymptomatic. In 16 there was a defect in vitamin- $B_{12}$ metabolism and in 12 there were neurological complications, not all of which were due to deficiency of $B_{12}$. They concluded, as did Montuschi, that "abnormal bacterial activity in the small intestine is an important factor in these patients."

This hypothesis is supported by the observation that patients with jejunal diverticulosis often fail to absorb test doses of radioactive vitamin $\mathbf{B}_{12}$, but their absorption becomes normal when they are treated with oral broadspectrum antibiotics. ${ }^{6} 81113$ These findings have suggested that there may be stagnation of intestinal contents in the diverticula, encouraging the growth in the small intestine of an abnormal bacterial flora which interferes with the absorption of vitamin $B_{12}$. It is generally considered that bacteria do this by ingesting the dietary $B_{12}$ in competition with their host, ${ }^{1315}$ but the true explanation may well be more complex. ${ }^{16}$

The diagnosis of jejunal diverticuiosis should be suspected in any elderly patient who develops unexplained steatorrhoea or in whom megaloblastic anaemia responding to treatment with vitamin $B_{12}$ is associated with free hydrochloric acid in the gastric juice. The distinction from

\footnotetext{
1 Edwards, H. C., Diverticula and Diverticulitis of the Intestine. 1939. John

Case, J. T., J. A imer. med. Ass., 1920, 75, 1463.

Osler, W., Ann. anat. Surg., 1881, 4, 202.

Flynn, R., Aust. and N.Z. J. Surg.. 1933, 3. 192

Montuschi, E., Proc roy. Soc. Med.. 1949, 42, 868.

Badenoch, J., Bedford. P. D., and Evans, J. R.. Quart. J. Med.. 1955, 24. 321

Dick, A. P.. Brit. med. J.. 1955 1. 145.

- Halsted, J. A., Lewis, P. M.., and Gasster, M., Amer. J. Med.. 1956, 20, 42 Krevans, J. R., Conley, C. L., and Sachs, M. V.. J. chron. Dis.. 1956, 3. 234.

10 Gellman, D. D., Lancet, 1956, 2, 873

Mollin, D. L., Booth. C. C., and Baker, S. J., Brit. J Harmat., 1957, 3 412

Watkinson, G., Feather, D. B., Marson. F. G. W., and Dosselt, J. A. Dn:s, A.. and Girdwood. R. H.. Quart. J. Med.. 1940, 24, 333 14 Cooke. W. T., Cox. E. V.. Fone. D. J.. Meynell. M. J., and Gaddie, R..

15 Dona!dson. R. M.. Gastroenterology, 1962, 43. 271

16 Booth C. C.. and Heat's. J. Gut. 1962, 3, 70

17 Johnson, $\mathrm{P} \ddot{\mathrm{M}}$.. and Wysor, W. G.. Arch. intern. Med.. 1961. 108. 370.
} 
Addisonian pernicious anaemia may be difficult in patients with achlorhydria and in some instances the two conditions may co-exist. ${ }^{11}$ Barium follow-through examination with a non-flocculating suspension of barium ${ }^{17}$ usually shows the diverticula, which are most striking in the proximal regions of the small intestine. ${ }^{1}$ The condition may sometimes be a chance finding on routine radiological examination and occasionally the diagnosis is made at laparotomy.

Treatment of the associated nutritional deficiencies with vitamin $B_{12}$ and a diet high in protein and low in fat is usually successful. Folic acid may occasionally be required, but because of the danger of precipitating neurological complications it should never be given alone. The steatorrhoea is frequently relieved by repeated courses of oral broad-spectrum antibiotics, of which the tetracyclines or erythromycin appear the most successful. Neomycin is reported to be ineffective in this condition. ${ }^{8}$ Surgical intervention is rarely necessary unless there are local abdominal complications, such as obstruction, perforation, or haemorrhage. ${ }^{1}$

\section{VARIABILITY OF ARTERIAL PRESSURE}

We have been made aware in recent times of "observer error" by which doctors differ in their judgment of symptoms and signs. Theoretically this could undermine confidence in the ability of our profession to reach any diagnosis. And yet by a sort of intuitive process which tends to weight the significance of each facet of clinical observation with something approaching its statistical value based on experience a final judgment of the nature of the patient's afflictions is reached; this usually carries a fair degree of precision and widespread professional agreement. Perhaps this constitutes the art of medicine, which will in the long run save diagnosis from becoming a matter for electronic computers or mechanical brains.

Recent population studies on levels of arterial pressure have led to long philosophical discussions and arguments on the levels of pressure at which normality ends and disease begins. While no one would admit to having any fixed rule about the situation, arterial pressures of about $150 / 90 \mathrm{~mm} . \mathrm{Hg}$ or over in the adult population are usually taken as an index of abnormality, particularly if associated with other manifestations of arterial disease, when the impression builds up to a conviction. Professor $T$. McKeown' and his colleagues have now published the follow-up readings of arterial pressure in some Birmingham and South Wales populations three to four years after first recording them. Certain subjects were excluded because they had suffered myocardial infarctions in the interval (it would be interesting to know about their previous blood pressures): others had died or were untraced. In the remaining subjects about $75 \%$ of the readings of systolic pressures were often found to be within $20 \mathrm{~mm}$. $\mathrm{Hg}$ higher or lower than the original reading, while diastolic pressures ware within the range of $10 \mathrm{~mm}$. $\mathrm{Hg}$ higher or lower. Less commonly these differences could reach extremes of 70 and $50 \mathrm{~mm}$. Ho respectively. Had these variations been recorded as differences from the average

\footnotetext{
McKeown. T.. Record. R. G., and Whitefield. A. G. W., Clin. Sct., 1963,
24. 437
}

of the two readings there would have been $10 \mathrm{~mm} . \mathrm{Hg}$ difference in the systolic and $5 \mathrm{~mm}$. $\mathrm{Hg}$ difference in the diastolic pressures. Another interesting point was that those whose first pressures were within the normal range (100-140 mm. $\mathrm{Hg}$ systolic) tended to show a rise at subsequent readings, while those with high pressure (160-220 $\mathrm{mm}$. $\mathrm{Hg}$ ) more frequently showed a decrease on later measurement.

These observations will occasion no great surprise to physicians experienced in this subject. Fluctuation of arterial pressure is characteristic of hypertension, especially in the benign phase, and sometimes the variation can be extreme. First readings often engender a little anxiety and tend to subside with familiarity. It has been truly said that the expression of either satisfaction or alarm on the doctor's face as he takes the pressure can alter the reading downwards or upwards. These observations of Mckeown and his colleagues are important in two ways. Firstly, they show the fallacies of judgment of the effects of milder hypotensive agents. Secondly, they reveal the gradual, fluctuating, up-and-down transition between normality and the established abnormality of hypertensive arterial disease.

\section{PASTEURIZATION OF LIQUID EGG}

After January 1, 1964, no liquid or frozen whole egg, whether home-produced or imported, may be used as an ingredient in the preparation of food for human consumption unless it has been pasteurized. Regulations ${ }^{1}$ to this effect have been made under the Food and Drugs Act. The liquid egg must be pasteurized according to the requirements laid down in Part $I$ of the Schedule of the Regulations and satisfy the $\alpha$-amylase test described in Part III of the Schedule. This important commodity, through its widespread use in food-manufacturing and catering establishments, including bakeries and hospitals, has for many years been responsible for outbreaks of paratyphoid fever and of food-poisoning infections with Salmonella typhi-murium, S. thompson, and other salmonella serotypes. Everyone who has the health of the country at heart will welcome the introduction of regulations designed to render the product safe.

The dangerous results of using bulked egg contaminated with $S$. paratyphi $B$ in bakeries making cream confectionery were discussed in these columns recently. ${ }^{2}$ It was clear from the epidemiological pattern of the outbreaks that repetition of similar incidents could be prevented only by treating bulked egg material at the production stage. The hygiene of poultry husbandry, of the stations where the eggs are "broken out," and of the bakery could not hope to control the spread of contamination by infected egg.

There will still be problems in regard to cracked eggs and those called "seconds." They are partly covered by the regulations, but the main volume of bulked egg should be made safe if they are observed.

\footnotetext{
I S.I. No. 1503, 1963. The Liquid Egg (Pasteurization) Regulations, 1963.

2 Brit. med. J.. 1963. 1, 1175

4 Anellis, A., Luhas, J., and Rayman, M. R., Food Res., 1954, 19. 377.

Brooks, J., J. Hyg. (Lond.), 1962, 60, 145.

1462 60, D. H., Monsey, J. B., Hobbs, B. C., and Smith, M. E., ibid. 1962. 60, 153

ihid., 1962, 60, 135.

Mth. Bull. Minist. Hith Lab. Serv., 1960, 19, 134.
.., and Hobbs, B. C.,
} 